\title{
FORMAÇÃO DE PROFESSORES, TRABALHO DOCENTE NO ENSINO SUPERIOR E MERCADO DE TRABALHO
}

\author{
Teachers' education, teaching work at \\ higher education and job market
}

\author{
Alda Junqueira Marin ${ }^{[a]}$, Noemi Bianchini ${ }^{[b]}$ \\ [a] Professora pesquisadora do Programa de Estudos Pós-Graduados em Educação: \\ História, Política, Sociedade da Pontifícia Universidade Católica de São Paulo (PUC-SP), \\ São Paulo, SP - Brasil, e-mail: aldamarin@pucsp.br \\ [b]Doutoranda do Programa de Estudos Pós-Graduados em Educação: História, Política, \\ Sociedade da Pontifícia Universidade Católica de São Paulo (PUC-SP), São Paulo, SP - \\ Brasil, e-mail: noemibianchini@hotmail.com
}

\section{Resumo}

Esta comunicação apresenta reflexões e resultados de um estudo sobre o trabalho docente no ensino superior problematizando-os em face das novas regulamentações para formar professores por meio da educação a distância. Para tanto, são desenvolvidos argumentos pautados em três focos: a regulamentação, dados quantitativos sobre abertura de vagas nessas

Rev. Diálogo Educ., Curitiba, v. 10, n. 29, p. 45-58, jan./abr. 2010 
modalidades de ensino e considerações sobre os efeitos da implantação no Brasil. As análises são realizadas com referenciais da área das Ciências Sociais. No primeiro conjunto de argumentos são analisadas as bases legais para a modalidade de educação a distância estabelecidas pela Lei de Diretrizes e Bases da Educação Nacional (Lei n. 9.394, de 20 de dezembro de 1996) e os posteriores decretos, portarias e resoluções, apontando os fundamentos de globalização utilizados para as ações políticas que alteraram o contexto da formação docente no Brasil. O texto apresenta argumentos pautados em dados quantitativos e espaciais no país corroborando as reflexões anteriores e apontando a massificação desse âmbito de escolaridade entre outros pontos. No terceiro foco são analisadas algumas consequências dessa implantação, apontando alterações no âmago do trabalho docente com o uso das novas tecnologias - além de alterações nas condições de trabalho e tensões já visíveis no mercado de trabalho.

Palavras-chave: Formação de professores. Trabalho docente. Educação a distância. Ensino superior. Mercado de trabalho.

\section{Abstract}

This presentation introduces reflections and results of a study about the teaching work at higher education, questioning them according to the new rules to form teachers by means of online education. In order to do this, arguments are developed based on three points: the regulation, quantitative data about the offer of vacancies on those teaching modalities and considerations about the effects of the implementation in Brazil. The analysis was accomplished based on Social Sciences. At the first group of arguments, the legal basis to the online education was analyzed, established by the Law of Guidelines and Basis of National Education (Lei de Diretrizes e Bases da Educação Nacional - Law n. 9.394, on December 20 th, 1996) and the following decrees and resolutions, pointing the fundaments of globalization used for the political actions which altered the context of teaching formation in Brazil. Then, there are arguments based on quantitative and spatial data in the country emphasizing the previous reflections pointing the enlargement of this kind of school, among other issues. At the third focus,

Rev. Diálogo Educ., Curitiba, v. 10, n. 29, p. 45-58, jan./abr. 2010 
Formação de professores, trabalho docente no ensino superior e mercado de trabalho

some consequences of this implementation were analyzed, showing alterations in the teaching work with the use of new technologies - besides the alterations of the work conditions and tensions which could be found already at the job market.

Keywords: Teachers' education. Teaching work. Distant education. Higher education. Job market.

\section{INTRODUÇÃO}

Este trabalho apresenta alguns resultados e reflexões iniciais de estudos sobre o trabalho docente no ensino superior, problematizando-o em face das novas regulamentações para formar professores por meio da Educação a Distância (EAD). A ideia central defendida aqui é a da precarização crescente do trabalho do professor no âmbito do ensino superior e as implicações para o mercado de trabalho desse profissional.

Para tanto são desenvolvidos argumentos pautados em três focos: a regulamentação, alguns dados quantitativos relativos à abertura de vagas nessas modalidades de ensino e considerações sobre alguns efeitos da implantação no Brasil.

A análise inicial, realizada com referenciais da área das Ciências Sociais, traz no primeiro conjunto de argumentos algumas bases legais para a modalidade de educação a distância estabelecidas pela Lei de Diretrizes e Bases da Educação Nacional (Lei n. 9.394, de 20 de dezembro de 1996) e os posteriores decretos, portarias e resoluções, apontando fundamentos utilizados para as ações políticas que alteraram o contexto da formação docente no Brasil.

A seguir, há exemplos de dados quantitativos e espaciais no país corroborando as reflexões anteriores, apontando a massificação desse âmbito de escolaridade entre outros pontos.

No terceiro foco são analisadas algumas consequências que caracterizam a precarização com essa implantação, apontando algumas alterações no âmago do trabalho docente com o uso das novas tecnologias - incluindo alterações nas condições de trabalho e tensões já visíveis no mercado de trabalho.

Rev. Diálogo Educ., Curitiba, v. 10, n. 29, p. 45-58, jan./abr. 2010 


\section{As novas regulamentações}

As regulamentações atuais sobre o ensino superior têm origem anterior. Já desde a década de 1970 entraram em vigor no país novas bases para a organização desse nível de ensino a partir da Reforma Universitária (SAVIANI, 1997) e também desdobramentos que afetaram o ensino superior com a promulgação das novas diretrizes para o ensino de $1^{\circ}$ e $2^{\circ}$ graus que vieram com a Lei n. 5.692/71 (BRASIL, 1971). No que tange à primeira destaca-se aqui a síntese elaborada por Saviani (1997, p. 24), apontando as demandas contraditórias da referida lei: de um lado a demanda necessária de expansão e reorganização interna da universidade com mais verbas e autonomia para a pesquisa e, de outro, a demanda de grupos que "buscavam vincular mais fortemente o ensino superior aos mecanismos de mercado e ao projeto político de modernização em consonância com os requerimentos do capitalismo internacional". Nessa direção a lei regulamentou, sobretudo, os cursos de curta duração e a organização fundacional que permitiu a enorme expansão dos estabelecimentos de ensino superior. Já na segunda, com a expansão da obrigatoriedade da escolarização até os 14 anos e a reorganização curricular para essa faixa de atendimento, a expansão do ensino superior no âmbito da formação de professores foi inevitável. Como decorrência ampliou-se o recrutamento de milhares de novos professores, sobretudo na rede de instituições privadas, um contingente que precisou ir se formando, gerando, por sua vez, a ampliação dos cursos de pós-graduação.

Sob o impacto de tais características, só enunciadas aqui, o ensino superior, no que tange à formação de professores, existiu até a década de 1990, passando por críticas e tentativas de reformulação dos estudos e movimentos de entidades na área.

Com a Lei n. 9.394/96 (BRASIL, 1996) e seus desdobramentos, a expansão teve novo impulso, pois regulamentou novas modalidades de cursos superiores de formação em geral e de professores em particular, possibilitando a expansão da privatização e mercantilização do ensino superior com graves consequências em relação à qualidade dos cursos oferecidos, dentre as quais se destaca, aqui, a relativa ao trabalho de professores.

No conjunto das regulamentações destacam-se, neste artigo, as possibilidades de criação dos centros universitários, as parcerias com instituições públicas, os cursos a distância e as necessidades de formar milhares de professores ainda sem certificação de ensino superior.

Rev. Diálogo Educ., Curitiba, v. 10, n. 29, p. 45-58, jan./abr. 2010 
Formação de professores, trabalho docente no ensino superior e mercado de trabalho

Com total autonomia para a criação de novos cursos, sem a exigência de se constituírem como instituições de pesquisa com os parâmetros das universidades, os centros universitários constituíram o modelo ideal para a ampliação de vagas, sobretudo em licenciaturas, que visavam suprir a demanda de cursos para a formação de professores para atuarem na Educação Básica e, em especial, para a formação de professores que já atuavam na Educação Infantil e nas séries iniciais do Ensino Fundamental. Estes possuíam a formação no âmbito do ensino médio e precisavam buscar a formação no âmbito do Ensino Superior, também por exigência do Art. 62 da LDB (BRASIL, 1996).

A Proposta de Formação de Professores (BRASIL, 2000), documento que apresenta novos princípios norteadores para a formação de professores para atuar na Educação Básica, traz, em sua introdução, a urgência de se buscar novos caminhos para suprir as demandas de formação de professores capazes de melhor formar crianças e jovens que frequentam as escolas públicas.

Com base nesse documento, a Resolução n. 1/2002 (BRASIL, 2002a) apresentou as Diretrizes Curriculares para a Formação de Professores da Educação Básica no âmbito do Ensino Superior, possibilitando a implementação de inúmeros programas de formação de professores em serviço.

Outro importante documento para delinear o contexto que pretende justificar a expansão do Ensino Superior e suas condições de implementação é o Plano Nacional de Educação (PNE) (BRASIL, 2001), que estabeleceu metas para serem alcançadas nos próximos dez anos após sua promulgação.

Nesse documento, assim como nos citados anteriormente, épossível observar a ideologia neoliberal, segundo Maués (2003), no que se refere aos programas e metodologias que poderiam ser adotados para a formação de professores, no âmbito do Ensino Superior, para a Educação Básica com destaque para os que já atuavam e que pretendiam atuar na Educação Infantil e nas séries iniciais do Ensino Fundamental. O PNE trouxe a possibilidade de formação em massa desses profissionais que não possuíam a titulação mínima exigida pela LDB/96. Assim, esse documento possibilitou a ampliação de cursos oferecidos por meio da colaboração entre a União, os Estados e os Municípios (BRASIL, 2001).

A modalidade a distância também aparece no Plano Nacional de Educação (PNE) (BRASIL, 2001) como importante instrumento de formação

Rev. Diálogo Educ., Curitiba, v. 10, n. 29, p. 45-58, jan./abr. 2010 
e capacitação de professores em serviço. Desde 1993 essa intenção havia sido apresentada no Conselho de Reitores das Universidades Brasileiras (CRUB). Propunha-se um Consórcio Interuniversitário de Educação Continuada e a Distância (BATISTA, 2002). Desde então emanaram várias modalidades, tais como a Universidade Virtual Pública do Brasil (UNIREDE) em 2000, para atender o ensino fundamental, e a Universidade Virtual do Brasil (UVB), que engloba diversas instituições privadas.

Paralelamente a esses acontecimentos, já estavam em curso experiências de Educação a Distância em universidades diversas no país, segundo Oliveira (2005).

A proposta de Reforma da Educação Superior do Governo Lula, mais especificamente o "Pacto de Educação pelo Desenvolvimento Inclusivo" e o recém-lançado Programa "Universidade Aberta do Brasil - UAB" (BRASIL, 2005a), também colocaram a Educação a Distância como uma das estratégias eficientes para a "democratização" do acesso à educação superior.

Assim, o discurso sobre cursos superiores oferecidos a distância vem para convencer e manipular o julgamento daqueles que sonham participar da competitividade do mercado de trabalho e necessitam de formação para graduarem-se em curto prazo, a preços acessíveis e em locais de fácil acesso.

Quem ousaria afirmar que ter acesso ao ensino superior não é uma necessidade social?

Nesse contexto, justificam-se as parcerias realizadas entre as instituições públicas e privadas, municípios e escolas particulares para oferecerem ensino superior por meio de Educação a Distância. Essas parcerias garantiram a infraestrutura necessária para que, até 2007, 889 cursos a distância fossem oferecidos em polos localizados em um grande número de municípios brasileiros.

Entre o grande número de diferentes propostas para aberturas de novos cursos e turmas nas mais diversas áreas do conhecimento, encontra-se o Edital de Seleção do Programa Universidade Aberta do Brasil (BRASIL, 2006b, 2007). Nele estão explicitadas as condições para propostas de parcerias para participação como Polo Municipal de Apoio Presencial, por parte dos municípios (individual ou coletivamente organizados), dos Estados brasileiros e do Distrito Federal.

De acordo com o documento citado, a proposta de polo de apoio presencial precisará garantir infraestrutura física e logística de

Rev. Diálogo Educ., Curitiba, v. 10, n. 29, p. 45-58, jan./abr. 2010 
Formação de professores, trabalho docente no ensino superior e mercado de trabalho

funcionamento, pessoal especializado para recursos humanos, lista de cursos de interesse para os municípios e número de vagas pretendidas. Assim, certamente, para que se cumpram essas exigências, é possível inferir que os estados e municípios parceiros que tiverem maiores condições financeiras terão maiores condições de participar desses acordos e de se preparar para oferecer o maior número de cursos em um maior número de locais.

Como se vê, por essa síntese, as possibilidades abertas com a Lei n. 9.394/96 (BRASIL, 1996) e legislação correlata, instituições públicas federais, estaduais, municipais e centros universitários, por meio de parcerias com outras instituições públicas e privadas, podem ser consideradas responsáveis pela ampliação e implementação de cursos oferecidos, principalmente com metodologia semipresencial e a distância, em todo o território nacional.

\section{Alguns dados sobre o ensino superior e a formação de professores}

Dados apresentados pela Unesco, em 2003, sobre a Taxa de Escolarização Bruta ${ }^{1}$, indicavam que o Brasil tinha uma oferta de vagas no Ensino Superior próxima à da África do Sul e à do Paraguai.

Essa realidade, que já havia sido mais desfavorável nos anos de 1960, quando a mesma taxa atingia apenas $1 \%$ dos jovens com idade para iniciar o Ensino Superior (BRASIL, 2004), nos últimos 40 anos, expandiuse consideravelmente, ou seja, de 1960 para 2002, considerando as redes públicas e privadas, as matrículas cresceram 37 vezes.

As redes privadas, no entanto, foram as que mais ofereceram vagas, pois, segundo dados disponibilizados pelo MEC e pelo Inep em 2002, do total aproximado de 3,5 milhões de vagas oferecidas ${ }^{2}$, cerca

\footnotetext{
Taxa de Escolarização Bruta é a razão entre o total de matrículas na Educação Superior e a população na faixa etária correspondente.

2 Pela ordem, as instituições que se destacaram na oferta de vagas são: UNIP (88 mil alunos de graduação), Estácio de Sá (86 mil), Universidade de São Paulo (43 mil), Universidade Luterana do Brasil (42 mil), Universidade Bandeirante de São Paulo (35 mil), PUC-MG (34 mil), Universidade do Vale do Rio dos Sinos (32 mil), Universidade Estadual de Goiás (32 mil), Universidade Estadual do Piauí (31 mil, com câmpus também na Bahia e no Maranhão) e Universidade Federal do Pará (30 mil).
}

Rev. Diálogo Educ., Curitiba, v. 10, n. 29, p. 45-58, jan./abr. 2010 
de 2,5 milhões eram em instituições privadas de Ensino Superior. Desta forma, em apenas dois anos (2000-2002), houve aumento de 52\% (BRASIL, 2002b).

Para o Secretário de Educação a Distância do MEC, Ronaldo Mota, A EAD está "crescendo vertiginosamente, atendendo todos os níveis de ensino. O acréscimo da demanda reforça a idéia de que é uma modalidade de ensino capaz de transformar o processo educacional no país." (MOTA, 2006). Tem toda a razão o autor ao enfatizar a expansão, pois os números de estudantes matriculados em cursos superiores oferecidos por esses novos modelos incluindo a EAD no Brasil são a evidência desse crescimento e dessa possibilidade de transformação do cenário educacional brasileiro.

Dados divulgados no Anuário Brasileiro Estatístico de Educação Aberta e a Distância, da Associação Brasileira de Educação Aberta e a Distância (ABED, 2007), durante o $5^{\circ}$ Seminário Nacional de Educação a Distância, revelaram que, entre os anos de 2004 e 2006, houve aumento de $150 \%$ no número de alunos matriculados em instituições que ofertam EAD no Brasil, passando de 309.957 para 778.458 estudantes.

O número de instituições brasileiras com cursos credenciados também teve um aumento no mesmo período. Em 2004 eram 166 instituições, passando para 217 instituições em 2005, e atingindo 225 no ano de 2006, o que caracteriza um aumento de $36 \%$ (ABED, 2007).

A Universidade Aberta do Brasil, um dos programas recentes do Ministério da Educação, já citado, também coopera significativamente para o crescimento do ensino a distância superior por meio de parcerias. Em junho de 2007 era previsto que 174 polos iniciassem cursos superiores na modalidade a distância. Outros 117 ainda estavam em fase de avaliação e adaptação para iniciar as aulas em setembro, totalizando 292 polos em 288 municípios brasileiros, distribuídos em todos os Estados da União e ofertando 60 mil novas vagas em diferentes áreas de formação superior (BRASIL, 2005a).

Voltando aos dados publicados pelo Inep/SINAES (BRASIL, 2005b), e já focalizando os docentes que atuam no ensino superior, a tabela que apresenta Funções de Docentes em Exercício segundo o Ano Censo, no ano de 2005, havia um total geral de 292.504 professores que atuavam em instituições que oferecem Ensino Superior, o que não significa que atuassem só nos cursos oferecidos a distância. Esse é um dado relevante para a discussão do próximo item.

Rev. Diálogo Educ., Curitiba, v. 10, n. 29, p. 45-58, jan./abr. 2010 
Formação de professores, trabalho docente no ensino superior e mercado de trabalho

\section{A precarização do trabalho docente e o mercado de trabalho}

A precarização do trabalho docente nas IES (Instituições de Ensino Superior) no Brasil não tem constituído foco de grande interesse e poucos trabalhos têm sido realizados com referência a esse tema.

Reconhecendo a lacuna de estudos sobre o tema, este item propõe a discussão de dados iniciais sobre a intensificação, exploração e desvalorização do trabalho de docentes que atuam em instituições que oferecem cursos superiores a distância.

Retomando a mesma fonte de informação do final do item anterior verifica-se, pelos dados do Inep/SINAES (BRASIL, 2005b) sobre cursos de graduação oferecidos, na tabela que contém dados sobre recursos humanos, ou seja, na tabela que apresenta o total de Funções Docentes em exercício segundo o Ano Censo, do total geral de 292.504 professores contratados, 127.826 professores foram contratados como horistas. Assim, nas IES, havia mais de 125 mil docentes em regime "horista", o que representava $43,5 \%$ de todos os docentes ocupados no ensino superior no Brasil (BRASIL, 2005b).

O trabalho desses profissionais também é destaque aqui porque a análise da relação entre número de alunos matriculados nos cursos oferecidos presencialmente ou por meio da EAD e o número de professores contratados revela a exploração do trabalho docente exercido nessas instituições, pois, muitas vezes, o mesmo profissional é responsável pela construção do material impresso, pelas gravações de teleaulas ou aulas oferecidas por meio de web conferências, pela avaliação, pelo atendimento ao aluno via 0800, e-mails e outros tantos recursos utilizados pelo Ensino a Distância. O mesmo profissional, na maioria das vezes, é contratado para trabalhar em diferentes cursos de graduação, ou seja, já não interessa sua formação e área de atuação específica. Ele precisa ser um profissional polivalente.

Um exemplo concreto do que vem ocorrendo com professores é o de uma instituição localizada em um município no interior do Estado de São Paulo, pois, para um curso oferecido fora da sede da instituição, com recursos de tecnologia e mídias interativas, que já formou mais de dez mil alunos nos cursos Normal Superior e Pedagogia, de 2005 a 2007, cerca de apenas 20 professores foram contratados para gravar teleaulas, orientar trabalhos de pesquisa e de conclusão de curso, construir as avaliações, entre outras atividades. Desses 20 , nenhum possuía doutorado

Rev. Diálogo Educ., Curitiba, v. 10, n. 29, p. 45-58, jan./abr. 2010 
e a grande maioria estava cursando o mestrado e, hoje, apenas 10 continuam na instituição e orientam trabalhos de conclusão de curso.

Os contratos contemplam apenas as tarefas a serem realizadas e o professor vende seus serviços à instituição que pode replicar o material enquanto houver demanda pelo curso, ou seja, o mesmo material impresso ou gravado poderá ser replicado infinitamente ou até que necessite de reformulação. Além disso, muitos são contratados como profissionais administrativos e por esta razão não possuem ou não participam das políticas de progressão da carreira universitária. Este exemplo vem se repetindo na grande maioria de instituições privadas, ou não, que oferecem cursos por meio da EAD.

Além dessas questões relativas a tais profissionais há que se destacar, ainda, a existência e a atuação dos tutores no âmbito de tais cursos. No mesmo exemplo citado, foram atendidos, ou seja, deveriam ser certificados, até o final de 2008, 21.202 alunos, professores em exercício ou não, em 720 locais só no Estado de São Paulo. Isso significa, com boa aproximação, 720 tutores, um para cada local com atividade presencial diária na turma de alunos desempenhando todas as funções de um docente com aulas, tirando dúvidas relativas ao material vinculado, orientando os trabalhos de conclusão de curso em seu diaa-dia, organizando vivências pedagógicas e atividades técnicas acadêmicas. Tudo isso por um salário de $\mathrm{R} \$ 1.000,00$.

Diante de tal quadro, pergunta-se: que mercado de trabalho é esse?

\section{ALGUMAS CONSIDERAÇÕES}

Para fechar este texto, duas considerações devem ser feitas, e ambas relativas aos professores e seu trabalho diante do quadro que apenas se esboçou, dadas as limitações de um artigo.

A primeira delas se refere a todo o movimento enunciado da dominação do ensino superior à lógica de mercado do neoliberalismo, seja no âmbito público seja no âmbito privado e os desdobramentos dessa vontade política internacional de precarização, conforme nos diz Bourdieu (1998a), sobretudo, neste caso, a degradação acelerada desse nível de ensino e do trabalho dos agentes que aí desempenham funções variadas.

A segunda consideração se refere ao desdobramento dessas condições de trabalho e sua expansão.

Rev. Diálogo Educ., Curitiba, v. 10, n. 29, p. 45-58, jan./abr. 2010 
Formação de professores, trabalho docente no ensino superior e mercado de trabalho

Para Bosi (2007), esse processo pode ser considerado como a mercantilização da educação pública e, nesse sentido, progride combinado à transferência dos aportes patrimoniais, financeiros e humanos públicos, para a iniciativa privada, por meio, principalmente, de alterações na superestrutura jurídica do Estado.

Portanto, é possível considerar que tal crescimento de profissionais contratados para exercer o trabalho docente no ensino superior foi (e continua sendo) marcado pela flexibilização dos contratos trabalhistas. Essas possibilidades de diferentes maneiras de contratação, inclusive a que deixa o profissional em condições precárias e informais de trabalho, têm se tornado em medida para todo tipo de trabalho restante. Segundo Bosi (2007), este é o principal fundamento histórico do processo que atravessamos. E continua:

É nesse "Espelho de Próspero" às avessas que, por exemplo, os docentes considerados trabalhadores "formais" começam a se verem refletidos, sem necessariamente conseguirem entender as formas atuais do seu próprio trabalho como expressão da dominação capitalista.

Visualizar a totalidade desse processo requer adotar o pressuposto de que, para além da precarização do trabalho docente expresso nas "velhas" e "novas" formas de contratação, muitas mudanças foram introduzidas na rotina das atividades de ensino, pesquisa e extensão, desde, pelo menos, o governo Collor de Melo. Do ponto de vista do capital, trata-se de aumentar o trabalho docente em extensão e intensidade. [...] Desse modo, ao mudar as formas institucionais do trabalho docente força-se a mudança da rotina do trabalho docente (BOSI, 2007).

Por isso, segundo Bosi (2007), o risco de não decifrarmos essa realidade e desenvolvermos os melhores instrumentos de luta para combatêla reside, como foi na infância da luta de classes, em tornarmo-nos cada vez mais prisioneiros dessa lógica, como nossos "próprios cárceres".

Para o autor, as condições históricas da precarização do trabalho docente nas IES no Brasil carecem de problematização, reflexão e denúncia sistemáticas para que a Lei de Inovação Tecnológica nas IES públicas e as diversas regulamentações afeitas ao produtivismo possibilitado por ela possam e devam ser tratadas em cada órgão

Rev. Diálogo Educ., Curitiba, v. 10, n. 29, p. 45-58, jan./abr. 2010 
colegiado das universidades e seja enfrentado e superado esse processo de alienação, precarização e exploração do trabalho docente nas universidades privadas e públicas no Brasil.

A tecnocracia vigente (BOURDIEU, 1998b) precisa ser enfrentada por todos os malefícios que produz ("especialistas", "mercados financeiros", "explicações viezadas"), de modo a reinventar os serviços públicos por meio do auxílio das análises e ações rigorosas sob pena de que, pensamos, em pouco tempo nem mesmo esse "mercado" de trabalho no ensino superior exista para docentes - para não dizer do existente e em queda nas instituições que possuem cursos presenciais -, e sim o domínio, apenas pelos detentores, dos meios já prontos e com crescente homogeneização do alunado.

\section{REFERÊNCIAS}

ASSOCIAÇÃO BRASILEIRA DE EDUCAÇÃO ABERTA E A DISTÂNCIA (ABED). Anuário Brasileiro Estatístico de Educação Aberta e a Distância. Disponível em: <http:/ /www.abraead.com.br/anuario_2007.html >. Acesso em: 15 jul. 2007.

BATISTA, W. B. Educação à distância e o refinamento da exclusão social. Conect@, n. 4, fev. 2002.

BOSI, A. de P. A precarização do trabalho docente nas instituições de ensino superior. Educação \& Sociedade, Campinas, v. 28, n. 101, p. 1503-1523, 2007. Disponível em: <http://www.cedes.unicamp.br>. Acesso em: 15 fev. 2008.

BOURDIEU, P. A precariedade está por toda parte. In: BOURDIEU, P. Contrafogos: táticas para enfrentar a invasão neoliberal. Rio de Janeiro: Jorge Zahar, 1998a. p. 119-127.

Contra a destruição de uma civilização. In: BOURDIEU, P. Contrafogos: táticas para enfrentar a invasão neoliberal. Rio de Janeiro: Jorge Zahar, 1998b. p. 37-41.

BRASIL. Lei n. 9.394, de 20 de dezembro de 1996. Estabelece as diretrizes e bases da educação nacional. Diário Oficial [da] República Federativa doBrasil, Poder Legislativo, Brasilia, DF, 23 dez. 1996. p. 27833. Disponível em:<http://www6.senado.gov.br/ legislacao/ListaTextoIntegral.action?id=75723>. Acesso em: 23 mar. 2008.

Rev. Diálogo Educ., Curitiba, v. 10, n. 29, p. 45-58, jan./abr. 2010 
Formação de professores, trabalho docente no ensino superior e mercado de trabalho

Lei n. 5.692, de 11 de agosto de 1971. Fixa diretrizes e bases para o ensino de primeiro e segundo graus, e da outras providencias. Diário Oficial [da] República Federativa do Brasil, Poder Legislativo, Brasília, DF, 12 ago. 1971. p. 6377. Disponível em: <http://www6.senado.gov.br/legislacao/ ListaTextoIntegral.action?id=75576>. Acesso em: 23 mar. 2009.

MEC/Conselho Nacional de Educação. Proposta de Diretrizes para a formação de professores da educação básica em cursos de nível superior. Brasília, 2000. Mimeografado

Lei n. 10.172, 9 de janeiro de 2001. Aprova o Plano Nacional de Educação e dá outras providências. Diário Oficial [da] República Federativa do Brasil, Poder Legislativo, Brasília, DF, 10 jan. 2001. Disponível em: < http:/ /www.senado.gov.br/legislacao/ListaPublicacoes.action?id=231634>. Acesso em: 16 mar. 2008.

Resolução CNE/CP n ${ }^{\circ}$, de 18 de fevereiro de 2002. Insitui diretrizes Curriculares Nacionais para a Formação de Professores da Educação Básica, em nível superior, curso de licenciatura, de graduação plena. Brasília: MEC/CNE,2002a. Disponível em: <http://portal. mec.gov.br/cne/arquivos/ pdf/rcp01_02.pdf>. Acesso em: 16 mar. 2008.

Ministério da Educação e do Desporto. Instituto Nacional de Estudos e Pesquisas Educacionais Anísio Teixeira (INEP). Sinopse estatística da educação superior. Brasília, DF: INEP/MEC, 2002b.

Ministério da Educação e do Desporto. Instituto Nacional de Estudos e Pesquisas Educacionais Anísio Teixeira (INEP). Mapa da educação superior. Brasília, DF: INEP, 2004. p. 85.

Ministério da Educação e do Desporto. Universidade Aberta do Brasil. Brasília, DF: INEP/MEC, 2005a. Disponível em: <http:// www.uab.mec.gov.br/>. Acesso em: 17 jul. 2007.

Ministério da Educação e do Desporto. Instituto Nacional de Estudos e Pesquisas Educacionais Anísio Teixeira.(INEP). Cadastro Nacional de Docentes. Brasília, DF: INEP/MEC, 2005b. Disponível em: <http:// sinaes.inep.gov.br/sinaes/>. Acesso em: 15 mar. 2009.

O Edital de Seleção UAB n. 01/2006-SEED/MEC. Brasília, 2006. Disponível em: <http://www.uab.mec.gov.br/>. Acesso em: 05 dez. 2007.

Rev. Diálogo Educ., Curitiba, v. 10, n. 29, p. 45-58, jan./abr. 2010 
O Edital de Seleção UAB n. 01/2006-SEED/MEC. Brasília, 2007. Disponível em: <http://www.uab.mec.gov.br/>. Acesso em: 05 dez. 2007.

MARIN, A. J.; BIANCHINI, N. Formação de professores a distância: sinais oriundos da atuação de tutores. In: CONGRESSO ESTADUAL PAULISTA DE FORMAÇÃO DE EDUCADORES, 9., 2007. São Paulo. Anais... São Paulo: UNESP, 2007.

MAUÉS, O. C. Reformas internacionais de educação e formação de professores. Cadernos de Pesquisa, São Paulo, n. 118, p. 89-117, 2003.

MOTA, R. Mec tem boas perspectivas para o ensino a distância no Brasil. 2006. Disponível em: <http://www.abraead.com.br/artigos_ronaldo.html>. Acesso em: 17 jul. 2007.

OLIVEIRA, C. C. A formação superior de professores através de mídias interativas. 2005. Tese (Doutorado em Educação) - Universidade Estadual de Campinas, Campinas, 2005.

SAVIANI, D. A nova lei da educação. Campinas: Autores Associados, 1997.

Recebido: 04/09/2009

Received: 09/04/2009

Aprovado: $30 / 10 / 2009$

Approved: 10/30/2009

Rev. Diálogo Educ., Curitiba, v. 10, n. 29, p. 45-58, jan./abr. 2010 